\title{
Design of Electric Powered Bicycle
}

\author{
Dhanyashree G, Vijayasree M, Yogesh Kumar H S, Dinesh V, N. Lakshmipathy \\ Department of Electrical and Electronics Engineering \\ Dr. T. Thimmaiah Institute of Technology, Kolar Gold Fields, Karnataka, India \\ Hod.eee@drttit.edu.in
}

\begin{abstract}
An electric powered bicycle is a human electric hybrid vehicle and these are basically for the people who are expecting replacement for vehicles which run with the help of fossil fuels like bike, car etc. to get some exercise and to travel fast without other additional effort to reach the destination. The problems related to pollution and fossil fuel depletion has increased due to the large usage of vehicles for travelling. Therefore, by using an E-bike we can have an eco-friendly and energy efficient mode of transportation.With this vehicle, it is possible to arrive at the destination with an ease. For our paper, a model of bicycle which is power-assisted has been designed, built, tested and performance of two batteries is compared.
\end{abstract}

Keywords: Key words: Bicycle, PMDC motor, battery, control circuit, load, eco-friendly

\section{Introduction}

In the current scenario, global warming and scarcity of traditional resources are becoming major issues and people are attracted towards "clean" energies [1]. Due to these facts, the electric bicycle industry will surpass other agendas all over the world. Bicycles with a supporting electric engine belong to the category of innovative vehicles and are very much suitable for day-to-day life activities. Electric bikes will make more energy efficient and environment friendly mobility possible as they have the potential to solve climatic related problems and traffic jam problems[3] [5]. Therefore, a continuous trend towards electric bicycles can be expected in India. In order to make common citizens of our country to afford a comfortable life, it becomes necessary to manufacture electric bicycles at a cheaper price.

For stable operation of an electric bicycle, selection of parameters like motor, controller, battery are very important. In our paper, we have considered to compare two batteries and study the performance of the batteries. The electric bicycle is constructed for the same. 


\section{Methodology}

We need to build a basic framework initially and include a segment which is fundamentally helpful for each and every citizen. [2] The equipment's are selected based on, Intensity of the engine ,The weight factor, as any additional load on the framework would be inconvenient for the rider while accelerating the bicycle[4]. The kind of battery to be utilized, as the battery should have a longer life, should be financially suitable and should have less maintenance workTherefore, the equipment's used for our model are a Bicycle, Batteries (SMF battery- 12V, 7.5Ah; Lithium ion battery24V, 10Ah), Charger, Fly Wheel, Chain Drives, PMDC Motor (24V, 250Watt, 2650rpm ( $\pm 5 \%)$ ), Controller (24V, 250Watt).

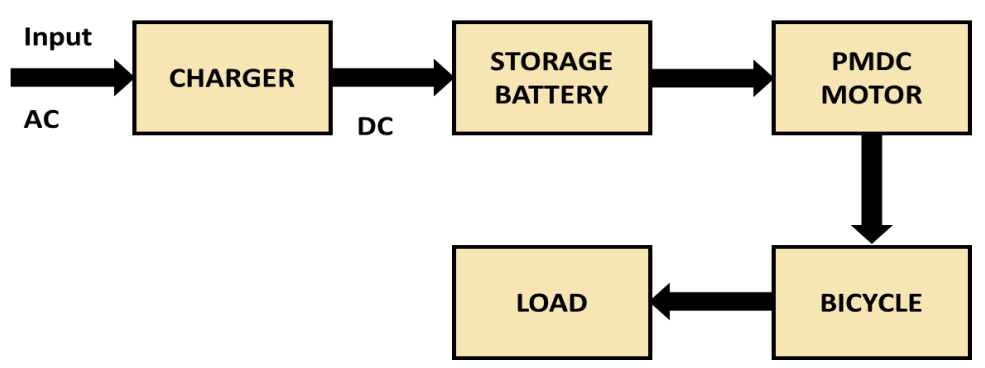

Fig 1: Block Diagram Of Electric Powered Bicycle

\section{$3 \quad$ Mounting of Components}

Motor: The 250W PMDC motor is linked with a flywheel using the sprocket,. Advantages of PMDC motor

- Motor size is small

- Low price

- No copper losses in field circuit and does not require field winding

Batteries: The SMF batteries are placed on the rear rack of the bicycle. Four $12 \mathrm{~V}$ SMF batteries are used to power the motor, where the two batteries are connected in series and further these are connected in parallel combination forming a whole of battery producing $24 \mathrm{~V}$.

Advantages of SMF battery,

Less expensive and simple tomanufacture

Low self-discharge

To study the performance of the bicycle when it uses Lithium-ion battery, the motor terminals are connected to the Li-ion battery.

Advantages of Lithium ion battery, 
- Highest energy density to weight ratio

- Eliminates need for periodic care for a long life

- Has no memory effect

Throttle: The throttle is fitted to the handle of the bicycle and the gear of the gear can be adjusted. The power from the battery is used by the motor when the throttle is operated [3]. The power utilized depends on the extent to which the throttle is twisted/turned. We have used full twist throttle for our model.

Controller: The light is placed in the front side of the bicycle between the handle bars and the lock for the bicycle is placed on the crossbar, the motor is connected to the controller.

The controller consists of various wires which may be different in various other types of controllers. To ensure right wiring connections we must know the wiring diagram of the controller [4]. Most e-bike controllers have wires which connects battery, bicycle brakes, throttle or Pedal Assist System (PAS). The advanced controllers have wires to connect speedometer and other display components, LED light, etc.

The components such as throttle, brake lever, front light, hall sensors are connected/linked with the controller as per the wiring specifications shown in Fig2.

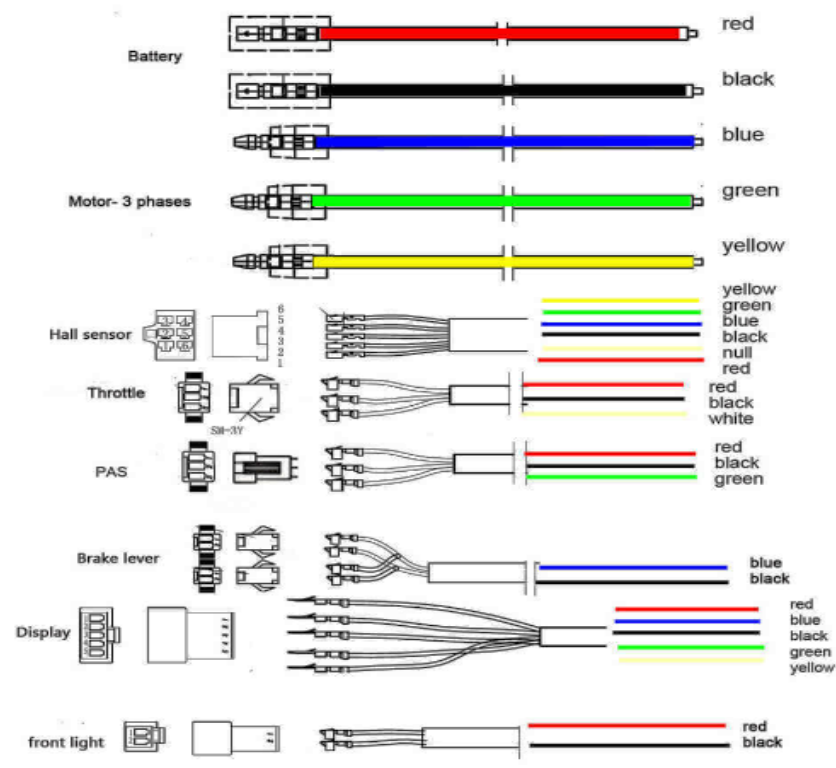

Fig 2: Wire specifications of the controller

\section{Functions of Motor Controller}

- Over-voltage protection 
- Low-voltage protection

- Over-temperature protection

- Over-current protection

The completely mounted E-Bike is as shown in the below figure,

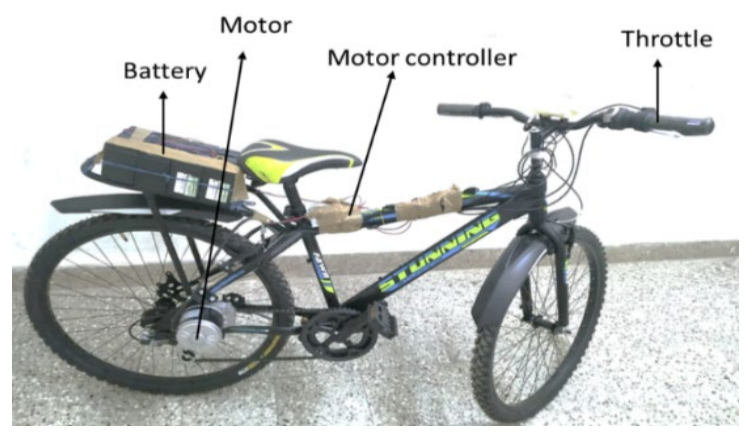

Fig 3: View of Electric Powered Bicycle

\section{$4 \quad$ Experimental Analysis}

The generalized circuit diagram for the electric powered bicycle is shown in Fig 4. The controller in whole describes the motor controller connected with throttle and other components. To determine the voltage value and current value that is used to rotate the wheel, ammeter and voltmeter should be used. We have used two multimeters to note the voltage value and current value drawn.

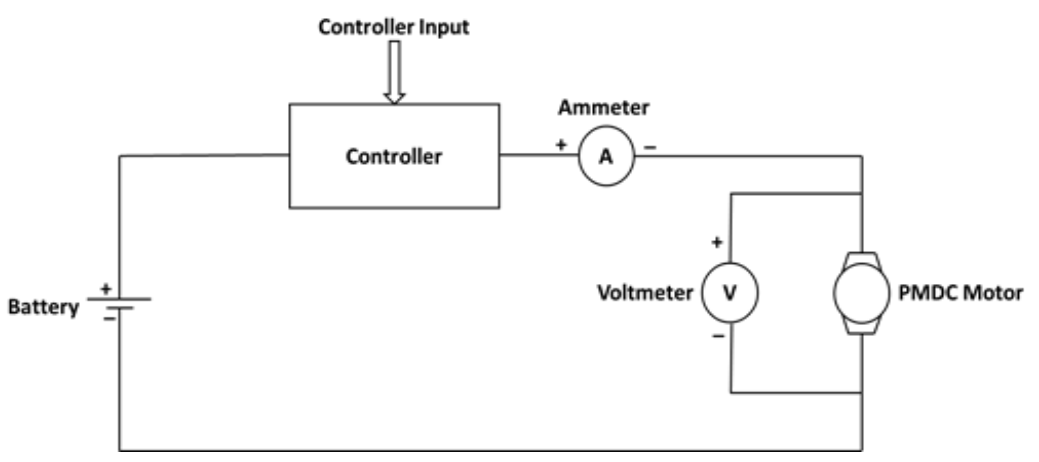

Fig 4: Circuit diagram of electric powered bicycle

\section{$5 \quad$ Procedure}

The connections are made as shown in Fig 4 where the multi-meters are connected in series with the controller circuit and in parallel with the PMDC motor accordingly. 
The knob of the multi-meters is kept at the DC point of both voltage $(200 \mathrm{~V})$ and current (20A).

A radium sticker is attached to the tire of the wheel to calculate the no. of rotations of the wheel. Tachometer is used to measure the rotation of the wheel.

Throttle is twisted/turned allowing the motor to rotate and the amount of current drawn for a particular voltage is noted down along with the wheel rotation in RPM. The values are noted until the maximum voltage is reached.

The same procedure is followed for Lithium-ion battery as well.

\section{Comparison of Performance of Batteries}

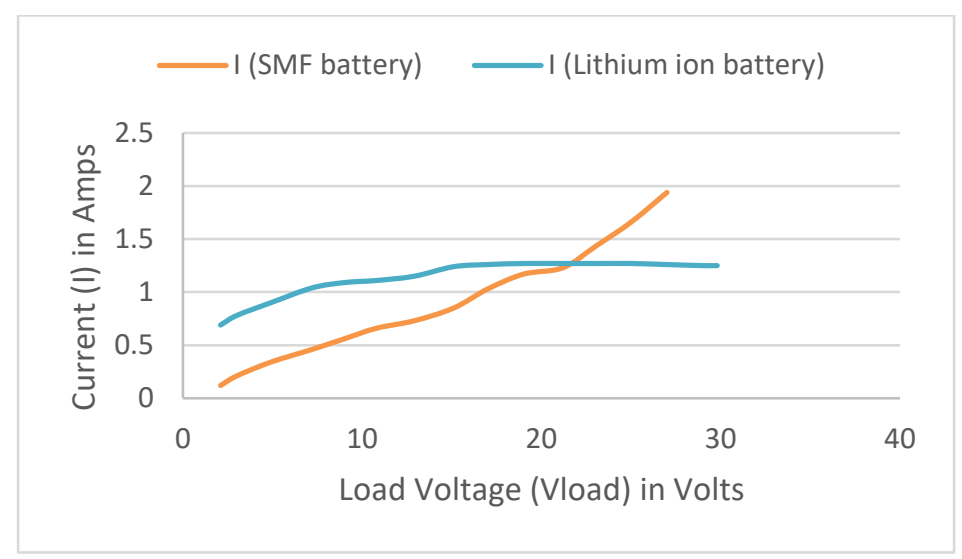

Fig 5 (a): Load Voltage v/s Current

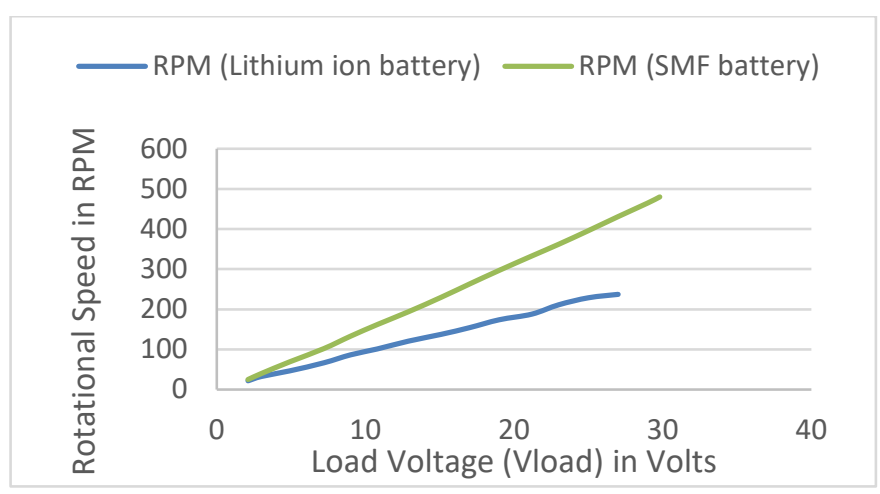

Fig 5 (b): Load Voltage v/s Rotational speed 


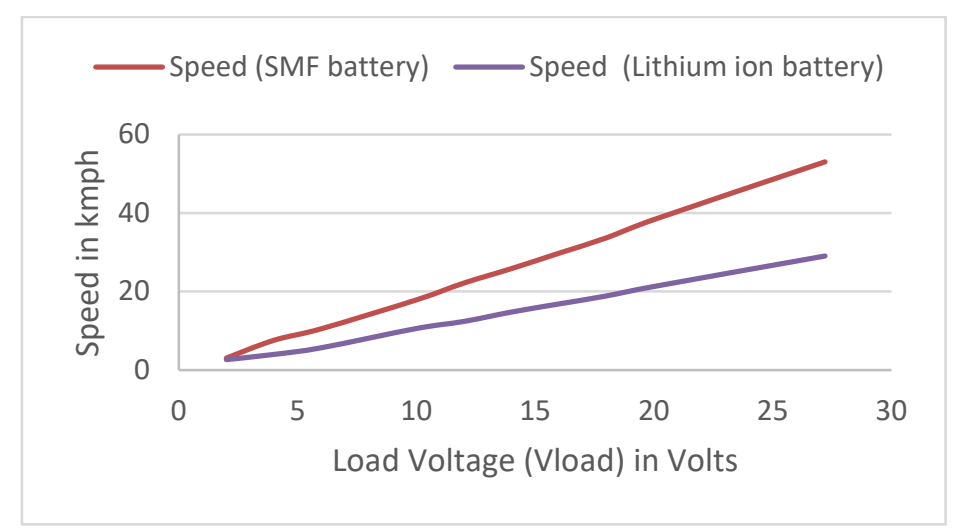

Fig 5 (c): Load Voltage v/s Speed of bicycle for Li-ion battery

\section{Conclusion}

Electrical bicycles give a clean and more economical solution to the energy crises which we are facing at present. In this paper we successfully mounted the components and analyzed the performance of electric bicycle by giving proper inputs. The performance of both batteries is recorded and graphs are plotted for the same. In terms of cost, Li-ion battery is greater than SMF battery. But, in terms of stabilized performance and weight constraints, Li-ion battery is better than the SMF battery.

\section{References}

1. Vivek V Kumar, Karthik A, AjmalRoshan, Akhil J Kumar, "Design and Implementation of Electric Assisted Bicycle with Self Recharging Mechanism", proceedings of International Conference On Innovations \& Advances In Science, Engineering And Technology [IC - IASET 2014].

2. RamchandraNittala, G. Sridhar Babu, V. Sumadeepthi, "Power E- Bicycle" in page no. proceedings of International Journal for Research in Applied Science \& Engineering Technology (IJRASET), Volume 6 Issue V, May 2018.

3. Kumar, S.S., Ahmed, S.T., Vigneshwaran, P. et al. Two phase cluster validation approach towards measuring cluster quality in unstructured and structured numerical datasets. J Ambient Intell Human Comput (2020). https://doi.org/10.1007/s12652-020-02487-w

4. Ahmed, S.T., Sankar, S. \& Sandhya, M. Multi-objective optimal medical data informatics standardization and processing technique for telemedicine via machine learning approach. J Ambient Intell Human Comput (2020). https://doi.org/10.1007/s12652-020-02016-9 
5. S. T. Ahmed and S. Sankar, "Investigative Protocol Design of Layer Optimized Image Compression in Telemedicine Environment", Procedia Computer Science, vol. 167, pp. 2617-2622, 2020, [online] Available: https://doi.org/10.1016/j.procs.2020.03.323 